\title{
Effect of apparent temperature on daily emergency admissions for mental and behavioral disorders in Yancheng, China: a time-series study
}

\author{
Min Min ${ }^{1}$, Tingting Shi ${ }^{1}$, Pengpeng Ye ${ }^{2}$, Yuan Wang ${ }^{2}$, Zhenhai Yao ${ }^{3}$, Shun Tian ${ }^{4}$, Yun Zhang ${ }^{1}$, Mingming Liang ${ }^{1}$, \\ Guangbo Qu', Peng Bi ${ }^{5^{*}}$, Leilei Duan ${ }^{2^{*}}$ and Yehuan Sun ${ }^{1^{*}}$ (i)
}

\begin{abstract}
Background: Very few studies have focused on the relationship between ambient apparent temperature (AT) and admission of mental and behaviour disorders (MDs). Therefore, a time-series study was conducted in Yancheng, China, to explore the effects of AT on the daily emergency admissions of patients with MDs over the period of 2014-17.

Methods: A quasi-Poisson generalized linear model (GLM) combined with a distributed lag non-linear model (DLNM) was adopted to explore the associations after adjusting for time trend, day of the week, humidity, sunshine duration, rainfall, holidays and air pollutants. In the subgroup analysis, the modification effects of age and sex were also examined.

Results: Overall, 8438 cases of MDs emergency admissions were identified. With the apparent temperature with the minimum number of admissions $\left(-3.4^{\circ} \mathrm{C}\right)$ serving as a reference, a positive correlation emerged between high AT and daily emergency admissions of patients with MDs in Yancheng, China, with the lagged effect of 1 to 5 days. The subgroup analysis demonstrated a positive relationship between AT and MDs emergency admissions among males and individuals younger than 45 years old, with no lagged effect.

Conclusions: The results will provide important scientific evidence for mental health policy-makers and practitioners for possible intervention, especially among the vulnerable populations.
\end{abstract}

Keywords: Apparent temperature, Hospital emergency admissions, Mental and behavioral disorders, Time-series analysis

\section{Background}

Mental disorders (MDs) include depression, bipolar disorder, schizophrenia, mental disability and developmental disorders, including autism [1], and collectively account for approximately $6.2 \%$ of the total global disease burden when measured in disability-adjusted life years (DALYs) [2]. Worldwide, approximately 350 million people suffer from depression, 60 million people from bipolar affective disorder, 47.5 million from dementia, and 21 million from schizophrenia and other

\footnotetext{
*Correspondence: peng.bi@adelaide.edu.au; duanleilei@ncncd.chinacdc.cn; yhsun_ahmu_edu@yeah.net

${ }^{5}$ School of Public Health, University of Adelaide, Adelaide, SA 5005, Australia ${ }^{2}$ Center for chronic noncommunicable diseases, Chinese center for disease control and prevention, Beijing 100050, China

'Department of Epidemiology and Health Statistics, School of Public Health, Anhui Medical University, Hefei 230032, Anhui, China

Full list of author information is available at the end of the article
}

psychoses [1]. In China, the lifetime prevalence of all mental disorders except for dementia is approximately $16.6 \%$ [3], with total costs of $\$ 3665$ for each individual patient and $\$ 88.8$ billion for society as a whole in 2013 [4]. Previous studies have indicated that exposures to ambient particulate matter $\left(\mathrm{PM}_{10} ; \mathrm{PM}_{2.5}\right)$, nitrogen dioxide $\left(\mathrm{NO}_{2}\right)$ and sulphur dioxide $\left(\mathrm{SO}_{2}\right)$ are considered risk factors for MDs [5-7]. Ambient temperature is frequently reported to be associated with mental health around the world [8-11]. Apparent temperature (AT) is a composite indicator of ambient temperature, relative humidity and wind velocity, reflecting human thermal perception more objectively than temperature itself [12]. In addition, it has been reported to be more closely associated with mortality than other temperature variables [13]. While most of the above studies use temperature

(c) The Author(s). 2019 Open Access This article is distributed under the terms of the Creative Commons Attribution 4.0 International License (http://creativecommons.org/licenses/by/4.0/), which permits unrestricted use, distribution, and 
Table 1 The AIC values of models for various lag periods from lag1 to lag 30 days

\begin{tabular}{|c|c|c|c|c|c|c|}
\hline Lag (days) & 1 & 2 & 3 & 4 & 5 & 6 \\
\hline $\mathrm{AIC}$ & 7135.102 & 7125.197 & 7123.229 & 7111.478 & 7105.905 & 7109.386 \\
\hline Lag (days) & 7 & 8 & 9 & 10 & 11 & 12 \\
\hline AIC & 7106.372 & 7102.363 & 7099.484 & 7098.49 & 7092.935 & 7087.281 \\
\hline Lag (days) & 13 & 14 & 15 & 16 & 17 & 18 \\
\hline $\mathrm{AlC}$ & 7072.434 & 7069.653 & 7066.486 & 7061.328 & 7058.34 & 7054.769 \\
\hline Lag (days) & 19 & 20 & 21 & 22 & 23 & 24 \\
\hline AIC & 7048.753 & 7040.924 & 7037.055 & 7036.359 & 7025.311 & 7017.717 \\
\hline Lag (days) & 25 & 26 & 27 & 28 & 29 & 30 \\
\hline $\mathrm{AIC}$ & 7012.755 & 7007.583 & 6997.914 & 6991.915 & 6989.067 & 6985.077 \\
\hline
\end{tabular}

and mental health hospitalization as study variables, there have been a limited number of studies using AT to examine its effects on MDs emergency admissions, especially in developing countries, including China. Therefore, we conducted a time series study to explore the lag-exposure-response relationship between AT and the risk of emergency admissions of patients with MDs in
Yancheng, China, to provide scientific evidence for mental health prevention and intervention.

\section{Method}

\section{Study area and data collection}

The study area was located in Yancheng, a city of approximately 8 million people. Yancheng lies in the

Table 2 Characteristics of admissions for MDs and meteorological variables and air pollutants in Yancheng, China, 2014-17

\begin{tabular}{|c|c|c|c|c|c|c|c|c|c|c|c|}
\hline Group & Sum & Mean (SD) & P1 & P5 & P10 & P25 & P50 & P75 & P90 & P95 & P99 \\
\hline Total (F00-F99) & 8438 & $5.8(3.0)$ & 0 & 2 & 2 & 4 & 5 & 8 & 10 & 11 & 14.4 \\
\hline $\begin{array}{l}\text { MDs due to alcohol } \\
\text { (F10) }\end{array}$ & 6802 & $4.7(2.7)$ & 0 & 0 & 1 & 2 & 4 & 6 & 8 & 10 & 13 \\
\hline Male & 5889 & $4.1(2.4)$ & 0 & 1 & 1 & 2 & 4 & 5 & 7 & 8 & 11 \\
\hline Female & 2549 & $1.7(1.5)$ & 0 & 0 & 0 & 1 & 2 & 2 & 4 & 4 & 6 \\
\hline$<45$ years & 6038 & $4.1(2.4)$ & 0 & 1 & 1 & 2 & 4 & 6 & 7 & 9 & 11 \\
\hline$\geq 45$ years & 2400 & $1.6(1.4)$ & 0 & 0 & 0 & 1 & 1 & 2 & 3 & 4 & 6 \\
\hline $45-60$ years & 1911 & $1.3(1.2)$ & 0 & 0 & 0 & 0 & 1 & 2 & 3 & 4 & 5 \\
\hline$\geq 60$ years & 489 & $0.3(0.6)$ & 0 & 0 & 0 & 0 & 0 & 1 & 1 & 1 & 2 \\
\hline Warm (Apr to Sep) & 4134 & $2.8(3.5)$ & 0 & 0 & 0 & 0 & 0 & 5 & 8 & 9 & 12 \\
\hline Cool (Oct to Mar) & 4304 & $2.9(3.7)$ & 0 & 0 & 0 & 0 & 0 & 5 & 8 & 10 & 14 \\
\hline Apparent temperature $\left({ }^{\circ} \mathrm{C}\right)$ & - & $15.2(12.1)$ & -5.4 & -2.8 & -0.92 & 4.03 & 15.6 & 25.3 & 30.6 & 34.5 & 38.1 \\
\hline Mean temperature $\left({ }^{\circ} \mathrm{C}\right)$ & - & $15.7(9.1)$ & -0.7 & 1.3 & 3.1 & 7.3 & 16.7 & 23.4 & 27.0 & 29.3 & 32.2 \\
\hline Relative humidity (\%) & - & $76.1(13.4)$ & 45 & 51 & 56 & 67 & 78 & 86 & 93 & 96 & 100 \\
\hline Sunshine duration (h) & - & $5.2(3.9)$ & 0 & 0 & 0 & 0 & 6.0 & 8.5 & 10.1 & 10.9 & 11.8 \\
\hline Wind speed $(\mathrm{m} / \mathrm{s})$ & - & $2.5(1.1)$ & 0.6 & 1.1 & 1.3 & 1.7 & 2.3 & 3.0 & 3.8 & 4.3 & 5.6 \\
\hline Rainfall (mm) & - & $3.3(12.5)$ & 0 & 0 & 0 & 0 & 0.0 & 0.3 & 8.1 & 20.2 & 60.7 \\
\hline $\mathrm{BP}(\mathrm{hPa})$ & - & $1017.0(9.2)$ & 999.9 & 1003 & 1005 & 1009 & 1017 & 1024 & 1029 & 1032 & 1035 \\
\hline $\mathrm{PM}_{10}\left(\mu \mathrm{g} / \mathrm{m}^{3}\right)$ & - & $83.3(49.0)$ & 15.6 & 28.0 & 34.0 & 48.0 & 71.0 & 108.0 & 146.0 & 176.0 & 253.0 \\
\hline $\mathrm{PM}_{2.5}\left(\mu \mathrm{g} / \mathrm{m}^{3}\right)$ & - & $48.3(35.0)$ & 8.0 & 12.0 & 15.0 & 230.0 & 23.0 & 39.0 & 94.0 & 115.0 & 178.4 \\
\hline $\mathrm{SO}_{2}\left(\mu \mathrm{g} / \mathrm{m}^{3}\right)$ & - & $16.9(10.1)$ & 5 & 7 & 8 & 10 & 14 & 20 & 30 & 37 & 54 \\
\hline $\mathrm{CO}\left(\mathrm{mg} / \mathrm{m}^{3}\right)$ & - & $0.8(0.3)$ & 0.3 & 0.4 & 0.5 & 0.6 & 0.7 & 0.9 & 1.2 & 1.4 & 1.8 \\
\hline $\mathrm{NO}_{2}\left(\mu \mathrm{g} / \mathrm{m}^{3}\right)$ & - & $25.7(13.1)$ & 8 & 11 & 12 & 16.0 & 22.0 & 31.0 & 44 & 54 & 67 \\
\hline $\mathrm{O}_{3} \_8 \mathrm{~h}\left(\mu \mathrm{g} / \mathrm{m}^{3}\right)$ & - & $105.8(38.0)$ & 29.6 & 56.0 & 64.0 & 78.0 & 101.0 & 127.0 & 156.0 & 175.0 & 212.4 \\
\hline
\end{tabular}

P1, P5, P10, P25, P50, P75, P90, P95, P99: the 1th percentile, the 5th percentile, the 10th percentile, the 25th percentile, the 50th percentile, the 75th percentile, the 90 th percentile, the 95 th percentile, the 99th percentile; SD, standard deviation; BP, barometric pressure 


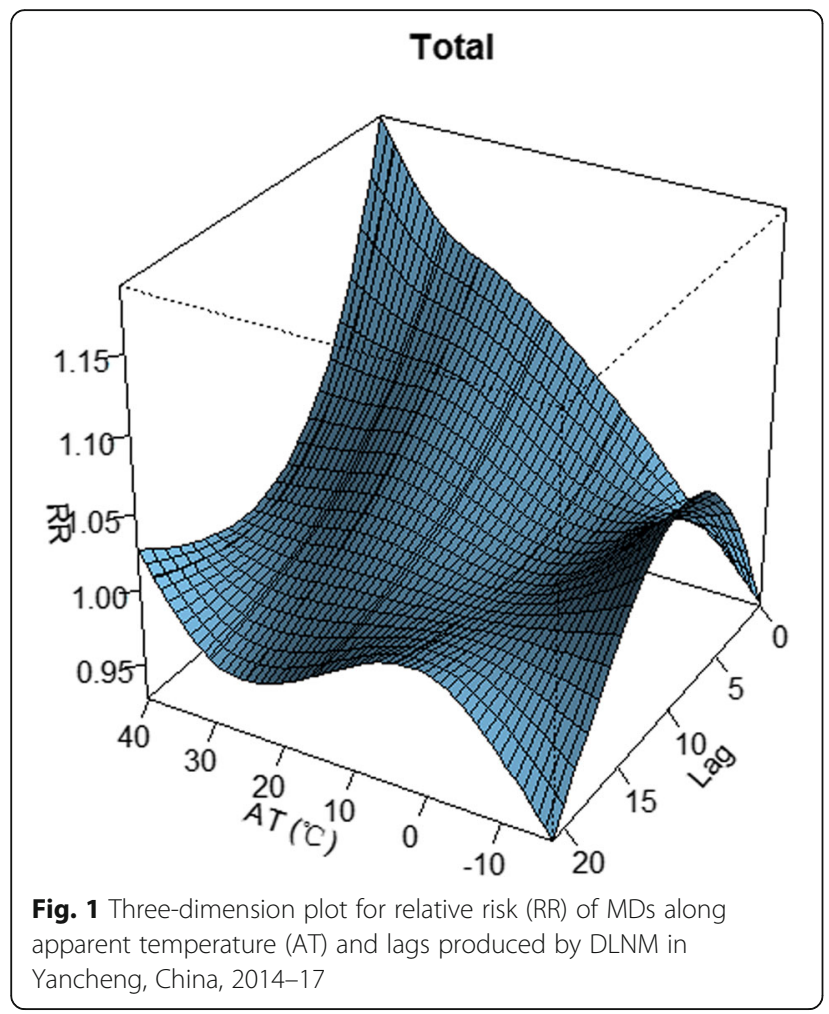

middle of the eastern coast of China $\left(33^{\circ} 38^{\prime} \mathrm{E}, 120^{\circ} 13^{\prime} \mathrm{N}\right)$ and has a typical subtropical monsoon climate with four distinct seasons.

Daily records of emergency admissions for MDs (ICD10 codes: F00-F99) from January 1, 2014, to December 31, 2017, were obtained from the hospital medical record systems of Yancheng city and included the date of admission and patients' age, gender, and occupation.

Daily meteorological data were collected from the China Meteorological Administration from 2014 to 2017, including daily average temperature, daily maximum temperature, daily minimum temperature, relative humidity, wind velocity, rainfall, sunshine duration and barometric pressure. Daily air pollution data for Yancheng, including $\mathrm{PM}_{2.5}$, $\mathrm{PM}_{10}, \mathrm{SO}_{2}, \mathrm{NO}_{2}, \mathrm{CO}$ and $\mathrm{O}_{3}$, were obtained from the website of the Environmental Monitoring Center. The apparent temperature was calculated with common meteorological indicators (average temperature, relative humidity and wind velocity) using the following specific formulas [14]:

$$
\begin{aligned}
& \mathrm{AT}=\mathrm{T}+0.33 * \mathrm{e}-0.70 * \mathrm{WS}-4.00 \\
& \mathrm{e}=\mathrm{Rh} / 100 * 6.105 * \exp .(17.27 * \mathrm{~T} /(237.7+\mathrm{T}))
\end{aligned}
$$

In the above formulas, $\mathrm{T}$ denotes the ambient average temperature $\left({ }^{\circ} \mathrm{C}\right)$; e refers to water vapor pressure $(\mathrm{hPa})$, which was calculated with the ambient average temperature and relative humidity using eq. (2); WS denotes wind speed $(\mathrm{m} / \mathrm{s})$; and $\mathrm{Rh}$ is relative humidity (\%).

Prior to data collection, this study was approved by the ethics committee of the Chinese Centers for Disease Control and Prevention Institute for Environmental Health and Related Product Safety (201606).

\section{Statistical analysis}

A generalized liner model (GLM) following a quasiPoisson distribution was applied, considering the overdispersion counts of daily emergency admissions of

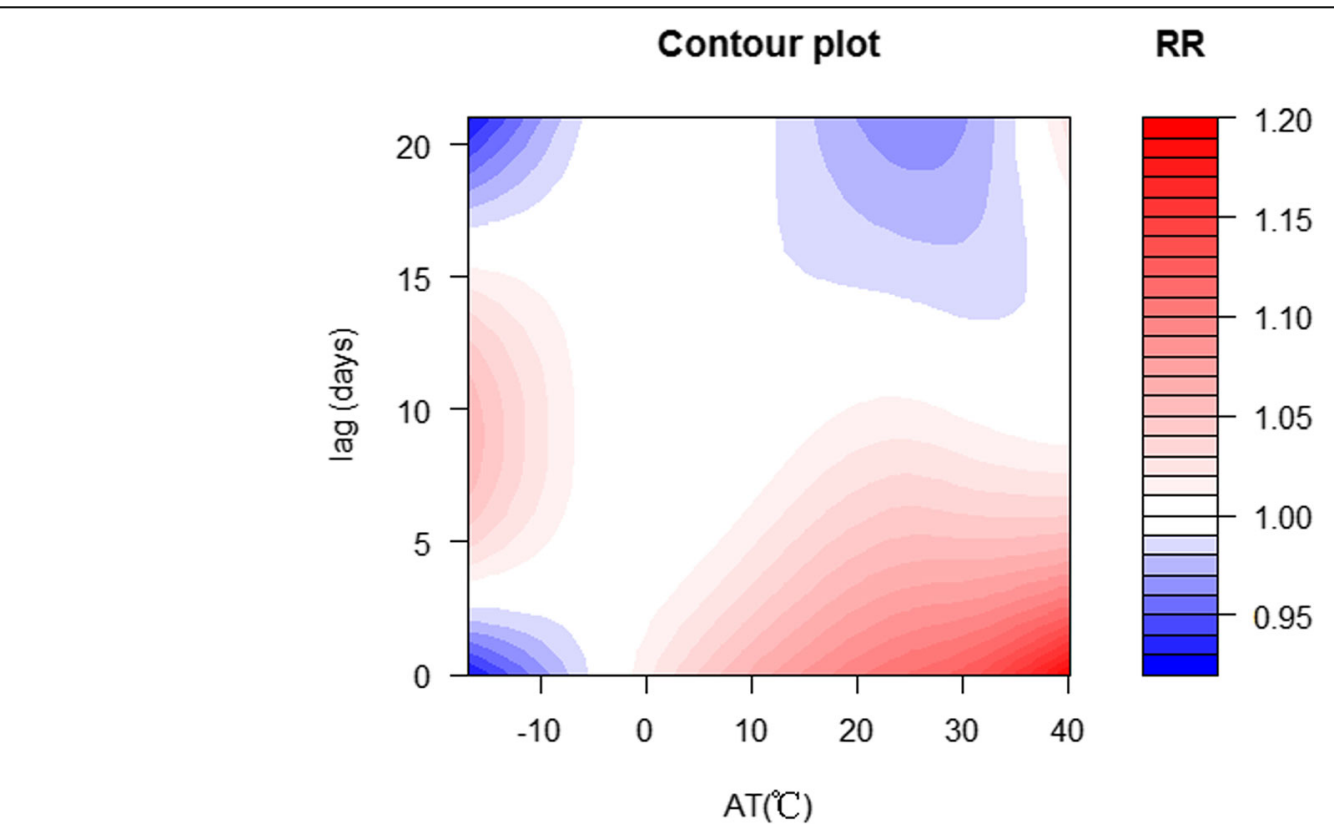

Fig. 2 Heat map for relative risk (RR) of MDs along AT and lags produced by DLNM in Yancheng, China, 2014-17 
patients with MDs, and the log function was used as the link function [15]. Spearman's correlation coefficients < 0.7 were used to select covariates to avoid multicollinearity. The Spearman correlations of different meteorological factors and air pollution are shown in Additional file 1: Figure S1. Finally, barometric pressure and $\mathrm{PM}_{10}$ were excluded, and daily mean temperature, relative humidity, sunshine duration, rainfall, $\mathrm{PM}_{2.5}, \mathrm{SO}_{2}, \mathrm{NO}_{2}$, and $\mathrm{O}_{3}$ were included. Moreover, the variance inflation factors (VIFs) for these variables were $2.108,2.304,1.905,1.174,2.464$, $2.570,2.003$ and 1.777 , respectively.

$$
\begin{aligned}
& \text { Yt } \sim \text { quasi Poison }(\mu \mathrm{t}) \\
& \begin{aligned}
\log (\mu \mathrm{t})=\alpha & +\beta \mathrm{ATt}, 1+\mathrm{ns}(\text { Time }, \mathrm{df}=4 * 4) \\
& +\mathrm{ns}(\mathrm{SDt}, \mathrm{df}=3)+\mathrm{ns}(\mathrm{Rht}, \mathrm{df}=3) \\
& +\mathrm{ns}(\text { Rainfallt }, \mathrm{df}=3)+\eta \mathrm{DOWNt} \\
& +\gamma \text { Holidayt }+\mathrm{ns}\left(\mathrm{PM}_{2.5}, \mathrm{df}=5\right)
\end{aligned}
\end{aligned}
$$

where Yt is the expected count of MDs cases for day t; $\alpha$ is the model intercept; $\mathrm{AT}_{\mathrm{t}, \mathrm{I}}$ is the DLNM cross-basis matrix of apparent temperature; 1 is the number of lag days; $\beta$ is the vector of regression coefficients for $\mathrm{AT}_{\mathrm{t}, \mathrm{l}}$; and $\mathrm{ns}()$ is the natural cubic spline. Additionally, 4 degrees of freedom (df) per year is used for time; $3 \mathrm{df}$ is used to adjust for possible impacts from humidity, sunshine duration, rainfall and air pollutants. DOW is the day of the week, with a reference day of Friday. Public holidays are also accounted for through the use of the categorical variable holiday.

According to the combination of AIC criteria and relevant literature, we chose 21 days as the maximum lag period in the model. The AIC values of lag1 to lag30 days are listed in Table 1. In the case of a nonlinear relationship [16], we calculated the relative risk (RR) with a 95\% confidence interval (CI) of specific ATs (10th percentile, 90th percentile) on daily MDs emergency admissions, with the AT corresponding to the minimum number of admissions as the reference (i.e., the AT with the lowest risk of total MDs admissions). Further analysis was conducted through stratification by sex and age group. Sensitivity analysis was performed by changing the $\mathrm{df}$ for time (4-6 df/year), sunshine duration (3-5 df), humidity (3-5 df), rainfall (3-5 df), and air pollutants $(3-5 \mathrm{df})$. All

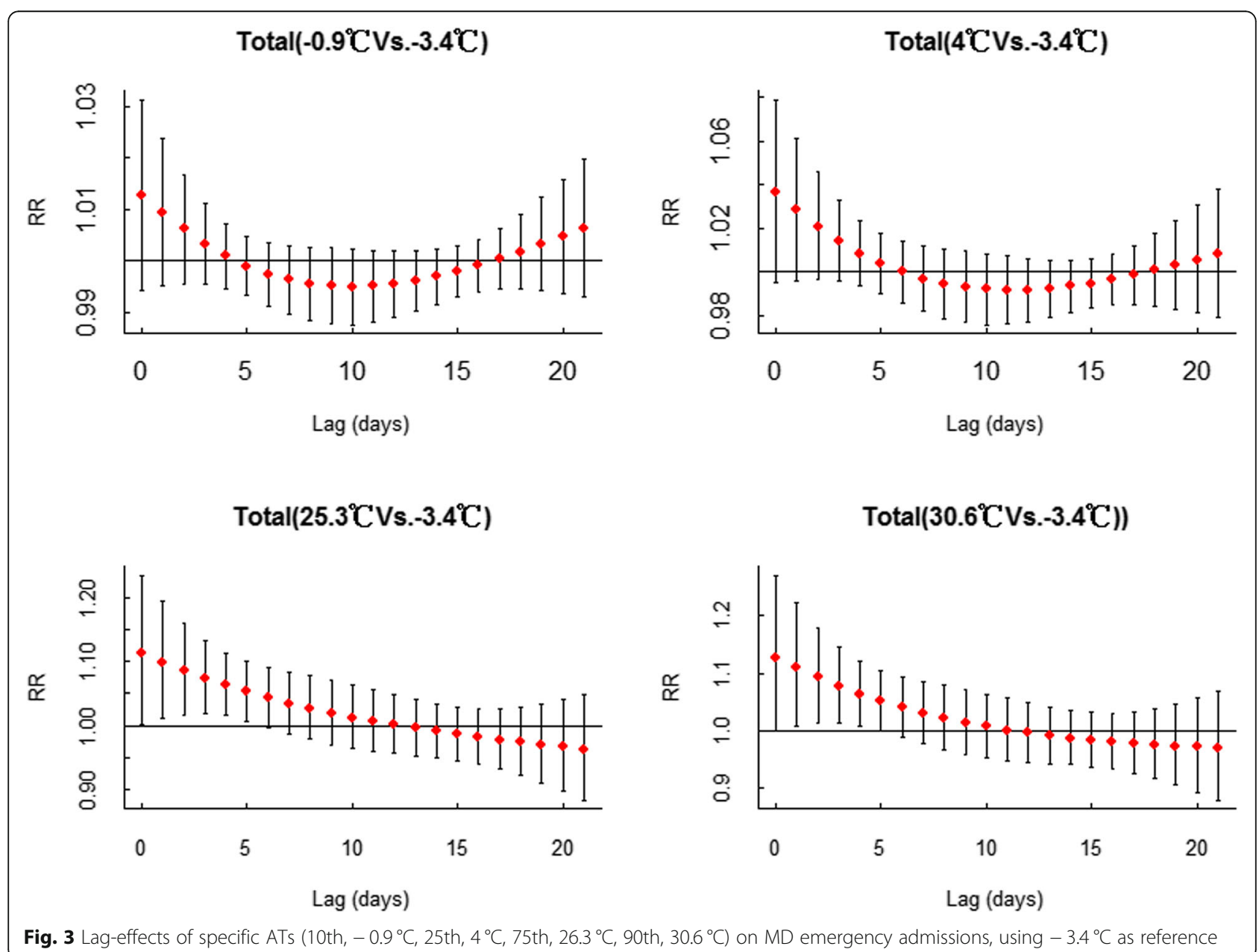


statistical analyses were performed using R software (Version 3.5.3) and the "dlnm" and "splines" packages [15].

\section{Results}

In total, 8438 hospital MDs emergency admissions were included over the study period, which encompassed 6802 admissions of patients with MDs due to alcohol use. Males and patients younger than 45 years accounted for 69.8 and 71.6\%, respectively, of MDs emergency admissions. Patients aged 45-60 years and older than 60 years accounted for 22.6 and $5.8 \%$, respectively. There were more MDs emergency admissions in cool seasons than in warm seasons (4304 vs. 4134). The daily AT and mean temperatures in Yancheng over the study period were $15.2^{\circ} \mathrm{C}$ and $15.7^{\circ} \mathrm{C}$, respectively. Characteristics of meteorological variables, pollutants and cases are shown in Table 2. The time series distributions of the total MDs cases, mean temperatures and ATs from 2014 to 2017 are presented in Additional file 1: Fig. S2, indicating a slight seasonal pattern.

The exposure-response association between MDs admissions and daily AT and lag days is shown in Figs. 1 and 2, qualitatively indicating that high AT had acute effects and lagged effects on admissions of patients with MDs.

Dose-response relationships between AT and MDs admissions over different lag days were also examined. The lagged effects from the ATs in different percentiles (P10, $-0.9{ }^{\circ} \mathrm{C}$; P25, $4{ }^{\circ} \mathrm{C}$; P75, $25.3^{\circ} \mathrm{C}$; P90, $30.6{ }^{\circ} \mathrm{C}$ ) are presented in Fig. 3. With the minimum admission apparent temperature of $-3.4^{\circ} \mathrm{C}$ as a reference, the single-day and cumulative lag effects of the 10th and 90th percentiles of AT on MDs admissions are shown in Table 3. In terms of single day lag effects, high AT had the greatest effect $(\mathrm{RR}=1.109,95 \% \mathrm{CI}: 1.007-1.222)$ at lag1, and the effect gradually decreased until the 5 th day $(R R=1.051,95 \%$ CI: 1.000-1.105). The cumulative lag effects of high ATs lasted until the 12th day ( $\mathrm{RR}=1.834,95 \% \mathrm{CI}: 1.016-$ 3.310). The lagged effects for low AT (both the 10th percentile and the 25th percentile) were not significant. In addition, Additional file 1: Figure $\mathrm{S} 3$ shows that specific ATs $\left(\mathrm{P} 10,-0.9^{\circ} \mathrm{C}\right.$; P25, $4{ }^{\circ} \mathrm{C}$; P75, $25.3^{\circ} \mathrm{C}$; P90, $\left.30.6^{\circ} \mathrm{C}\right)$ had no significant effect on admissions of patients with MDs due to alcohol.

Table 3 Single and cumulative effects estimates at various lag times (in days), with reference of $-3.4^{\circ} \mathrm{C}$

\begin{tabular}{|c|c|c|c|c|c|}
\hline \multirow{2}{*}{$\begin{array}{l}\text { Single- } \\
\text { day } \\
\text { (day(s)) }\end{array}$} & \multicolumn{2}{|c|}{ Relative risk (95\% confidence interval) } & \multirow{2}{*}{$\begin{array}{l}\text { Multi- } \\
\text { day } \\
(\text { day }(s))\end{array}$} & \multicolumn{2}{|c|}{ Relative risk (95\% confidence interval) } \\
\hline & $\mathrm{P} 10\left(-0.9^{\circ} \mathrm{C}\right)$ & $\mathrm{P} 90\left(30.6^{\circ} \mathrm{C}\right)$ & & $\mathrm{P} 10\left(-0.9^{\circ} \mathrm{C}\right)$ & $\mathrm{P} 90\left(30.6^{\circ} \mathrm{C}\right)$ \\
\hline 0 & $1.013(0.994-1.031)$ & $1.127(0.999-1.271)$ & $0-0$ & $1.013(0.994-1.031)$ & $1.127(0.999-1.271)^{*}$ \\
\hline 1 & $1.009(0.995-1.023)$ & $1.109(1.007-1.222)^{*}$ & $0-1$ & $1.022(0.989-1.056)$ & $1.250(1.006-1.551)^{*}$ \\
\hline 2 & $1.006(0.996-1.017)$ & $1.093(1.013-1.179)^{*}$ & $0-2$ & $1.028(0.985-1.073)$ & $1.365(1.021-1.825)^{*}$ \\
\hline 3 & $1.003(0.995-1.011)$ & $1.077(1.014-1.145)^{*}$ & $0-3$ & $1.032(0.981-1.085)$ & $1.471(1.040-2.079)^{*}$ \\
\hline 4 & $1.001(0.995-1.007)$ & $1.064(1.009-1.121)^{*}$ & $0-4$ & $1.033(0.978-1.091)$ & $1.564(1.062-2.305)^{*}$ \\
\hline 5 & $0.999(0.993-1.005)$ & $1.051(1.000-1.105)^{*}$ & $0-5$ & $1.032(0.974-1.093)$ & $1.644(1.081-2.052)^{*}$ \\
\hline 6 & $0.997(0.991-1.004)$ & $1.040(0.989-1.094)$ & $0-6$ & $1.029(0.970-1.091)$ & $1.710(1.095-2.671)^{*}$ \\
\hline 7 & $0.996(0.990-1.003)$ & $1.030(0.977-1.086)$ & $0-7$ & $1.025(0.966-1.088)$ & $1.762(1.103-2.815)^{*}$ \\
\hline 8 & $0.996(0.988-1.003)$ & $1.022(0.967-1.079)$ & $0-8$ & $1.020(0.961-1.084)$ & $1.801(1.102-2.941)^{*}$ \\
\hline 9 & $0.995(0.988-1.002)$ & $1.014(0.959-1.072)$ & $0-9$ & $1.016(0.955-1.080)$ & $1.826(1.092-3.052)^{*}$ \\
\hline 10 & $0.995(0.988-1.002)$ & $1.007(0.953-1.065)$ & $0-10$ & $1.010(0.950-1.075)$ & $1.839(1.074-3.150)^{*}$ \\
\hline 11 & $0.995(0.988-1.002)$ & $1.001(0.949-1.057)$ & $0-11$ & $1.005(0.943-1.071)$ & $1.841(1.048-3.236)^{*}$ \\
\hline 12 & 0.995 (0.989-1.002) & $0.996(0.946-1.049)$ & $0-12$ & $1.001(0.938-1.068)$ & $1.834(1.016-3.310)^{*}$ \\
\hline 13 & $0.996(0.990-1.002)$ & $0.992(0.944-1.042)$ & $0-13$ & $0.997(0.932-1.066)$ & $1.819(0.981-3.371)$ \\
\hline 14 & $0.997(0.992-1.002)$ & $0.988(0.941-1.036)$ & $0-14$ & $0.994(0.928-1.064)$ & $1.796(0.944-3.419)$ \\
\hline 15 & 0.998 (0.993-1.003) & $0.984(0.938-1.032)$ & $0-15$ & $0.992(0.925-1.063)$ & $1.768(0.905-3.452)$ \\
\hline 16 & 0.999 (0.994-1.004) & $0.981(0.933-1.032)$ & $0-16$ & $0.991(0.923-1.064)$ & $1.734(0.866-3.474)$ \\
\hline 17 & $1.000(0.994-1.006)$ & $0.979(0.926-1.034)$ & $0-17$ & $0.991(0.923-1.065)$ & $1.697(0.826-3.487)$ \\
\hline 18 & 1.002 (0.994-1.009) & $0.976(0.917-1.039)$ & $0-18$ & $0.993(0.924-1.068)$ & $1.657(0.785-3.498)$ \\
\hline 19 & $1.003(0.994-1.012)$ & $0.974(0.906-1.047)$ & 0-19 & $0.996(0.925-1.073)$ & $1.614(0.741-3.514)$ \\
\hline 20 & 1.005 (9.994-1.016) & $0.972(0.893-1.057)$ & $0-20$ & $1.001(0.927-1.081)$ & $1.568(0.694-3.544)$ \\
\hline 21 & $1.006(0.993-1.020)$ & $0.970(0.881-1.069)$ & $0-21$ & 1.007 (0.929-1.092) & $1.521(0.643-3.598)$ \\
\hline
\end{tabular}


The lag effects of air pollutants $\left(\mathrm{NO}_{2}, \mathrm{PM}_{2.5}, \mathrm{O}_{3}\right.$ and $\mathrm{SO}_{2}$ ) on MDs are demonstrated in Additional file 1: Table S1. A $10-\mu \mathrm{g} / \mathrm{m} 3$ increase, only $\mathrm{O}_{3}$ concentrations have an acute effect on MDs on the current day, with the RR of 1.007 (95\% CI, 1.001-1.014). However, after adjustments were made for daily mean temperature, this effect became insignificant, with the RR of 1.003 (95\% CI, 0.996-1.009).

\section{Subgroup analysis}

The effects of low AT $\left(\mathrm{P} 10:-0.9^{\circ} \mathrm{C}\right)$ on MDs admissions of different subgroups were not statistically significant (Fig. 4). In terms of high AT (P90: $30.6{ }^{\circ} \mathrm{C}$ ), its estimated effects on males and females were similar, but the $95 \%$ confidence interval of female patients was so wide that the effect was insignificant. For different age groups, high AT only showed a significant effect on the group aged $<45$ years (Fig. 5 ).

\section{Sensitivity analysis}

Sensitivity analysis showed that the effects were generally similar when the degrees of freedom were altered for the time trend $(\mathrm{df}=4-6)$, humidity $(\mathrm{df}=3-5)$, sunshine duration $(\mathrm{df}=3-5)$ and air pollutants $(\mathrm{df}=3-5)$ in the model (Figs. 6, 7, 8 and 9). The dose-response curve was similar before and after adjusting for air pollutants $\left(\mathrm{PM}_{2.5}, \mathrm{SO}_{2}, \mathrm{NO}_{2}\right.$ and $\left.\mathrm{O}_{3}\right)$ (Additional file 1: Figure S4). In view of all of the above results, our analysis was robust. Moreover, we replaced AT with daily mean temperature to compare the two indicators. Additional file 1: Figure S5 demonstrates that the effects of AT were similar to those of the daily mean temperature. Additionally, the values of the Mean Square Error (MSE) and AIC in model 1 when AT was adopted were approximately equal to those in model 2 (adopting daily mean temperature) (Additional file 1: Table S2).

\section{Discussion}

To our knowledge, this study was the first to explore both the non-linear and lagged effects of AT on total MDs emergency hospital admissions in China. We found that high AT had significantly nonlinear and delayed effects on MDs hospital emergency admissions. The effects appeared on the second day and can last for up

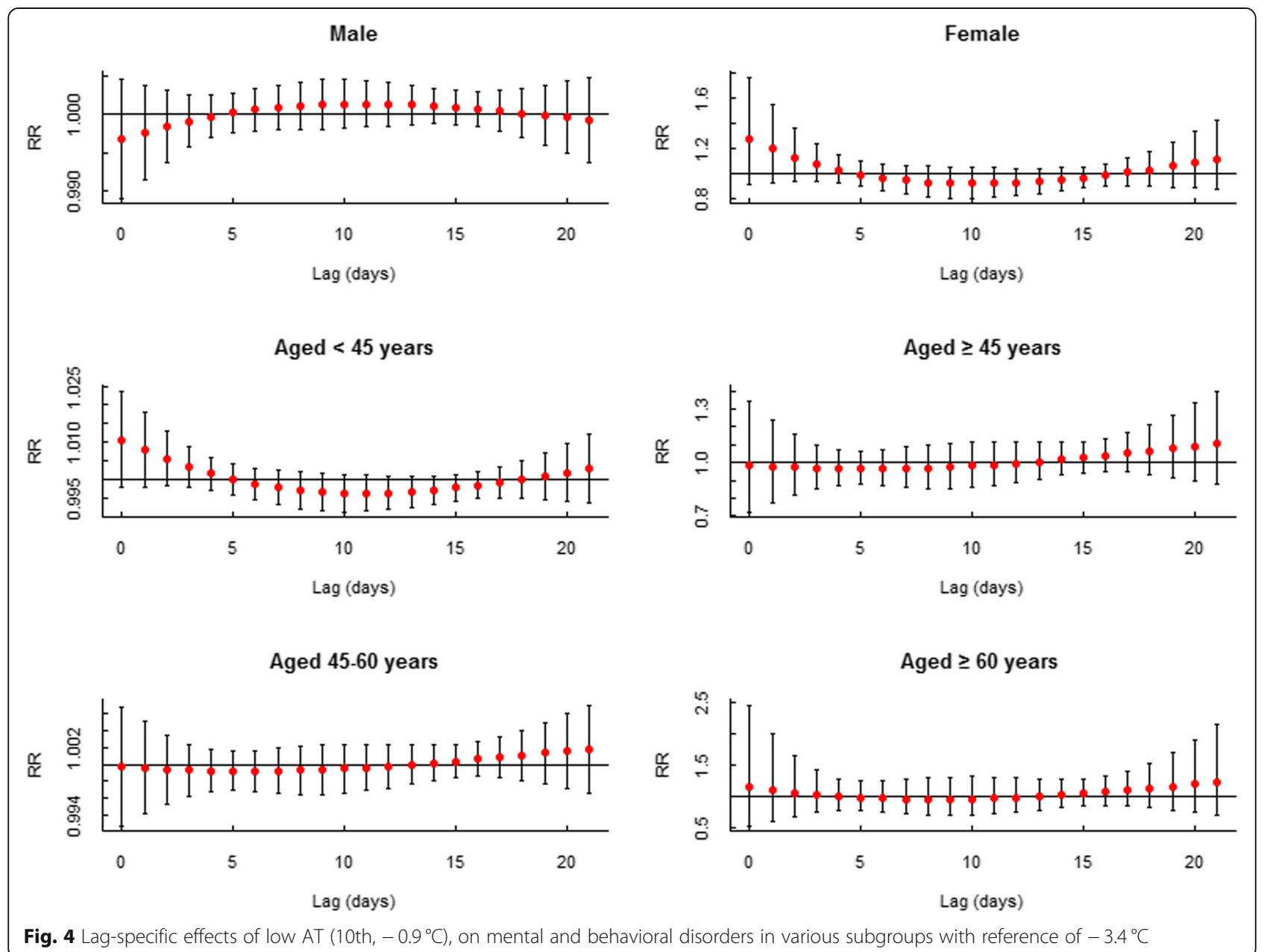




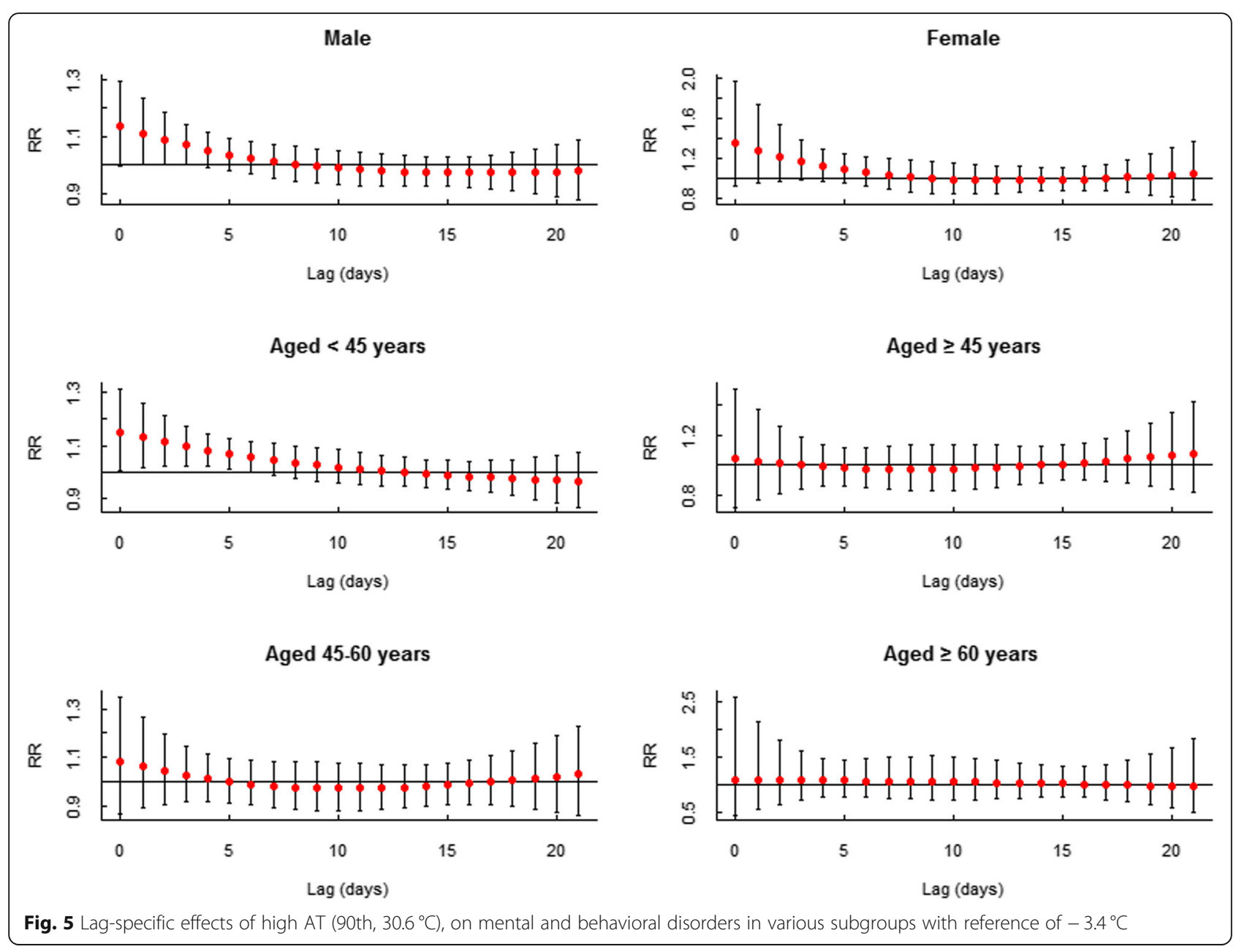

to 5 days. Moreover, the associations between AT and MDs admissions varied by age and gender, with male patients and patients aged $<45$ years being more vulnerable to higher AT (above the 75th percentile). However, no significant association for low AT was observed. Several studies have examined the effects of AT on mental health outcomes. One study in the USA reported that increasing AT was associated with emergency room visits for mental health-related outcomes, except for black and Asian patients [17]. Another study found that both high and low ATs were associated with admissions for schizophrenia in Hefei, China [16]. In addition, several studies have examined the relationship between ambient mean temperature and MDs admissions in Toronto, Canada [9]; Shanghai, China [11]; and Sweden [18]. The higher AT effect observed in our study was consistent with the effect of high ambient mean temperature reported in previous studies but differed from the results by Basu et al. [17]. Reasons for the inconsistency remained unclear, probably because we did not consider MD- related socio-economic factors in our statistical analysis due to data availability.

The potential biological explanations for the association between AT and MDs emergency admission risk varied for different mental disorders. AT is an index combining the environmental temperature, humidity and wind speed. High AT is usually uncomfortable for people, especially for people with mental disorders [19]. In a highAT (usually with high temperature and low humidity) environment, people with mental disorders may be agitated and become more aggressive and violent, which increases the risk of suicide and conflicts [20-22]. Hotter environments could disturb the metabolites of certain neurotransmitters, such as 5-hydroxytryptamine and dopamine, which are associated with the onset of depression and bipolar disorder [23-25]. In addition, high AT usually represents high environmental temperature, which could indirectly increase the risk of MDs emergency admission by influencing the effect of psychiatric medications used by individuals with mental illness [26]. Furthermore, some psychotropic drugs 
time $\mathrm{df}=\mathbf{4}$

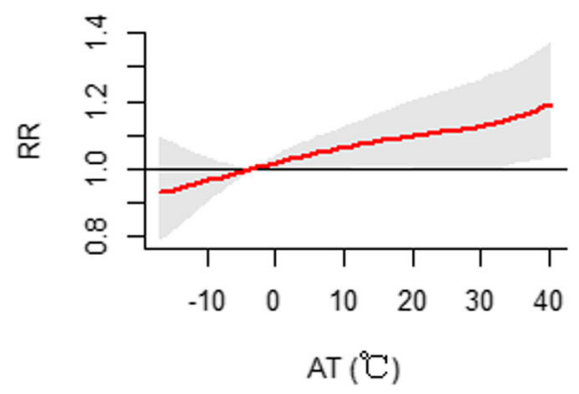

time $d f=6$

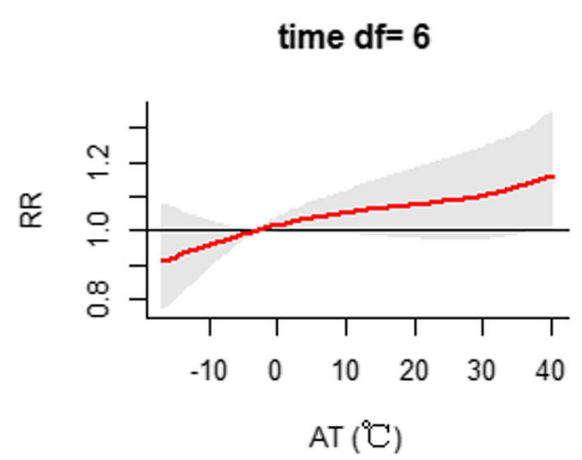

time $\mathbf{d f}=\mathbf{5}$

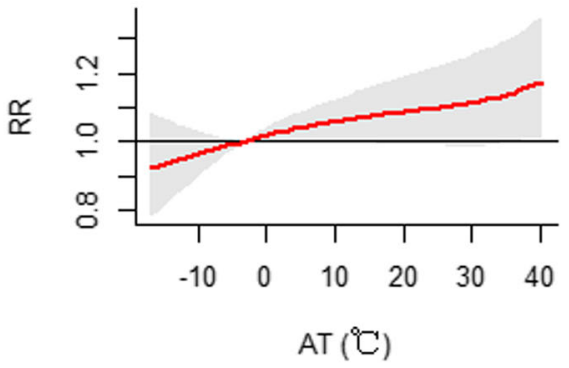

Fig. 6 Sensitivity analysis when altering the degrees of freedom $(\mathrm{df}=4-6)$ for controlling for the long-term trend and seasonality in the model

have side effects related to heat and increase patients' vulnerability in hot environments $[27,28]$.

Our paper has several strengths. First, our findings suggest that a combination of meteorological variables, such as ambient temperature, relative humidity and wind speed, significantly affect human mental health and behaviours. The health department, the health surveillance system and mental health institutions should comprehensively take a variety of meteorological factors into consideration when taking measures to decrease the risk of MDs admissions. Second, we included several air pollutants in the analyses that provided strong evidence for health authority. Third, we identified vulnerable MDs patients in this study, providing a specific target population for MDs control and prevention. At the community level, relevant agencies should inform the public of pending high AT weather and how long it could last. Accordingly, they should provide specific advice and open public cooling centres in a timely manner. At the hospital level, due to the lag effects of high AT on MDs emergency admissions, mental health institutions should arrange for emergency preparation in situations of high AT. At the individual level, MDs patients and their families should take note of early warning information, reduce outdoor activities during high AT periods, and turn on air conditioning.
Several limitations also need to be acknowledged. First, our study area was limited to a single city. Therefore, these findings should be interpreted with caution when generalized to other locations. Second, meteorological and pollution data obtained from fixed monitoring stations are approximate estimates of individual exposures, which may lead to an underestimate of correlation. Third, data on specific mental and behavioural disorders, such as depression, was so scarce that we could not perform subgroup analyses for specific mental and behavioural disorders. Moreover, we checked medical records to obtain data; thus, information on some crucial factors, such as socio-economic status and comorbidities, was not available. Finally, this time series analysis was an ecological study, and thus, an ecological fallacy may exist.

\section{Conclusions}

Our study showed that short-term exposure to high apparent temperature was associated with increased MDs emergency admissions in Yancheng, China. More studies are warranted to examine the association between apparent temperature and hospital admissions of patients with mental and behavioural disorders in various regions. In the future, AT might be used as an early warning indicator of emergency admissions of patients with mental and behavioural disorders. 


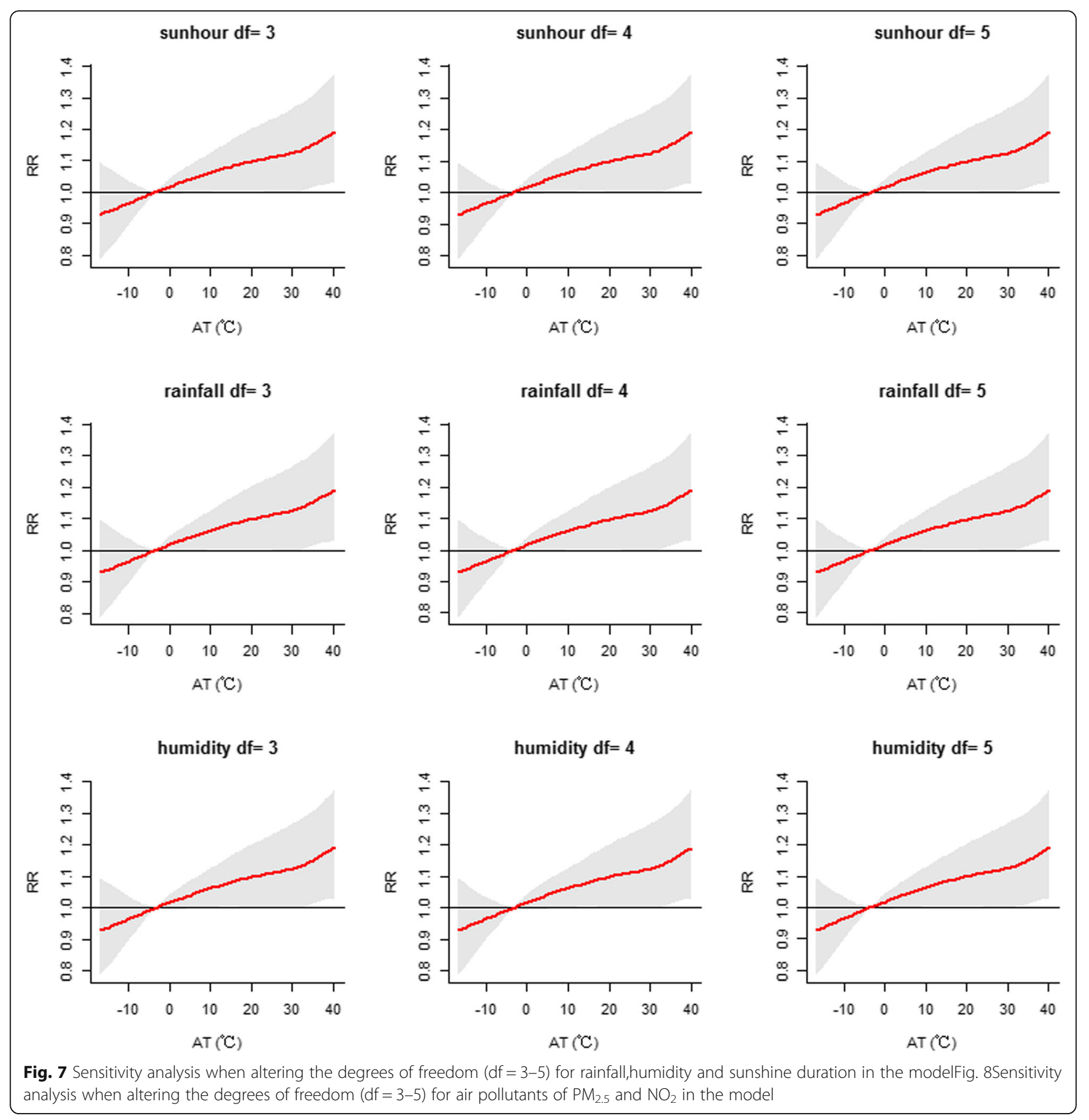


$\mathrm{PM} 2.5 \mathrm{df}=3$

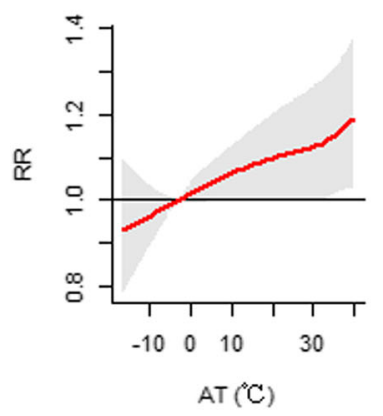

$\mathrm{NO} 2 \mathrm{df}=3$

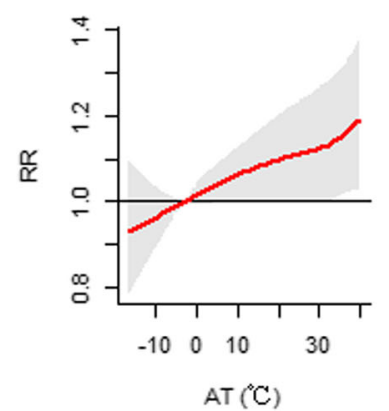

$\mathrm{PM} 2.5 \mathrm{df}=4$

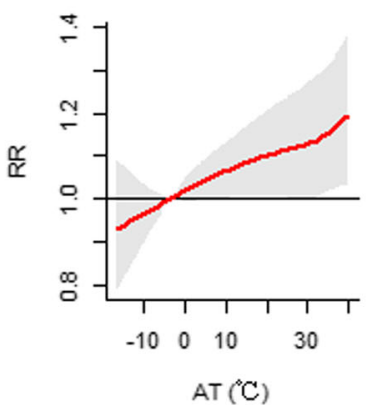

$\mathrm{NO} 2 \mathrm{df}=4$

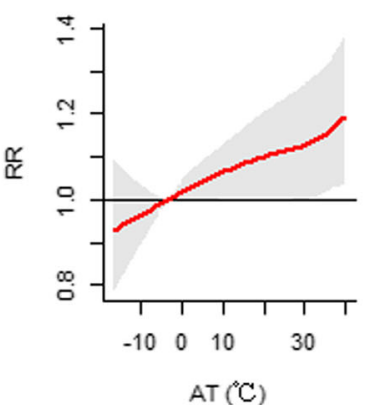

$\mathrm{PM} 2.5 \mathrm{df}=5$

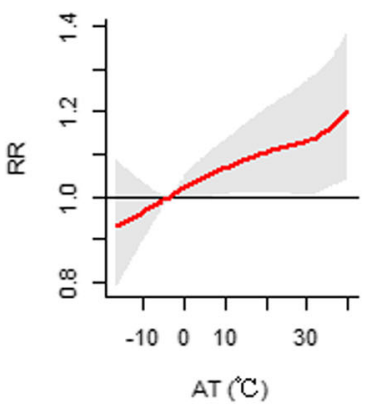

$\mathrm{NO} 2 \mathrm{df}=5$

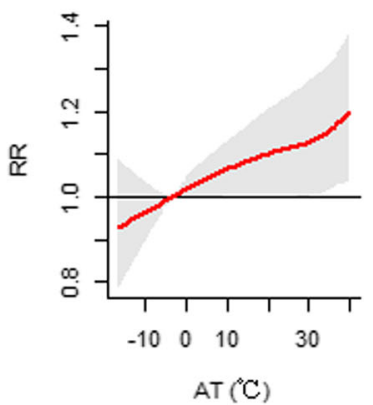

Fig. 8 Sensitivity analysis when altering the degrees of freedom $(\mathrm{df}=3-5)$ for air pollutants of PM2.5 and NO2 in the model

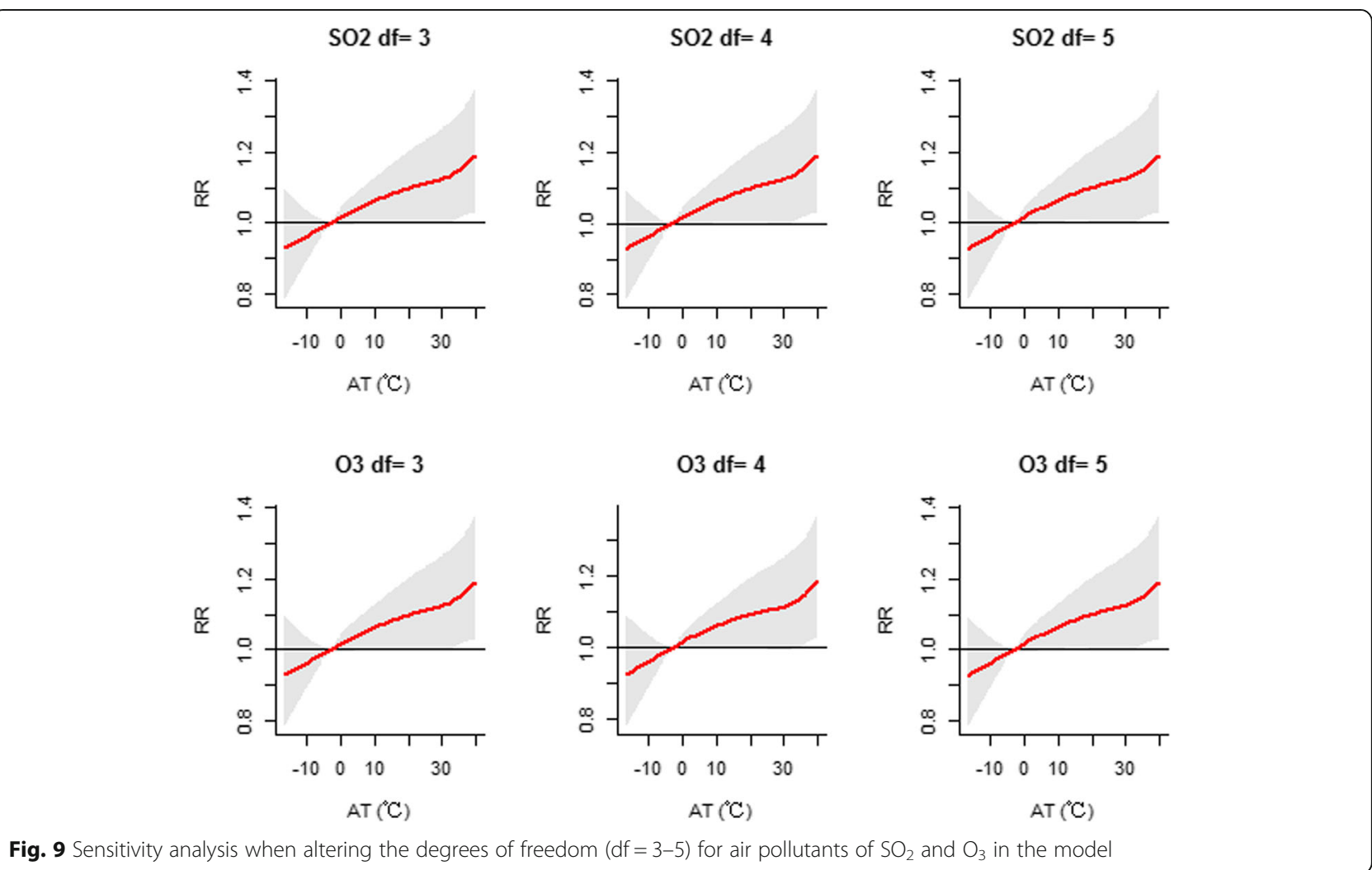

Fig. 9 Sensitivity analysis when altering the degrees of freedom $(\mathrm{df}=3-5)$ for air pollutants of $\mathrm{SO}_{2}$ and $\mathrm{O}_{3}$ in the model 


\section{Supplementary information}

Supplementary information accompanies this paper at https://doi.org/10. 1186/s12940-019-0543-x.

Additional file 1: Table S1. Results of the lag effects of air pollutants $\left(\mathrm{NO}_{2}, \mathrm{PM}_{2.5}, \mathrm{O}_{3}\right.$ and $\left.\mathrm{SO}_{2}\right)$ on MDs. Table S2. Fitting effects of two models were compared using AIC and MSE. Figure S1. Spearman's correlations between the different meteorological factors and air pollution. Figure S2. Time-series distribution of total MDs cases, mean temperature and AT in Yancheng, China, 2014-2017. Figure S3. Lag-effects of specific ATs (10th, $-0.9^{\circ} \mathrm{C}, 25$ th $, 4^{\circ} \mathrm{C}, 75$ th, $26.3^{\circ} \mathrm{C}, 90$ th, $30.6{ }^{\circ} \mathrm{C}$ ) on admissions of MDs due to alcohol, using $-3.4^{\circ} \mathrm{C}$ as reference. Figure S4. Sensitivity analysis before and after air pollutants $\left(\mathrm{PM}_{2.5}, \mathrm{SO}_{2}, \mathrm{NO}_{2}\right.$ and $\left.\mathrm{O}_{3}\right)$ taken into DLNM model in 2014-2017. (A, before air pollutants were included; B, after air pollutants were included). Figure S5. The dose-response relationship of DLNM model, included with AT and daily mean temperature as independent variables, respectively.

\section{Abbreviations}

AT: Apparent temperature; Cl: Confidence interval; DALYs: Disability Adjusted of Life Years; df: degrees of freedom; DLNM: Distributed lag non-linear model; GLM: Generalized linear model; MDs: Mental and behavioral disorders; MSE: Mean Square Error; RR: Relative risk; VIFs: Variance inflation factors

\section{Acknowledgements}

Not applicable

\section{Authors' contributions}

Conceptualization: MM; Methodology: MM, PY; Formal Analysis: MM; Resources: PY, YW, ZY, LD, YS; Writing - Original Draft Preparation: MM; Writing - Review and Editing: PY, YS, PB and LD; Supervision: TS; ST; YZ; ML;GG; Project Administration: PY, YW, YS, LD; Funding Acquisition: YS, LD. All authors read and approved the final manuscript.

\section{Funding}

This work was supported by special foundation of basic science and technology resources survey of ministry of science and technology of China (No.2017FY101200).

\section{Availability of data and materials}

The datasets used and/or analysed during the current study are available from the corresponding author upon reasonable request.

\section{Ethics approval and consent to participate}

Prior to data collection, this study was approved by the ethics committee from the Chinese Center for Disease Control and Prevention Institute for Environmental Health and Related Product Safety (201606).

\section{Consent for publication}

Not applicable

\section{Competing interests}

The authors declare that they have no competing interests.

\section{Author details}

${ }^{1}$ Department of Epidemiology and Health Statistics, School of Public Health, Anhui Medical University, Hefei 230032, Anhui, China. ${ }^{2}$ Center for chronic noncommunicable diseases, Chinese center for disease control and prevention, Beijing 100050, China. ${ }^{3}$ Anhui public meteorological service center, Hefei, Anhui 230011, China. ${ }^{4}$ Preventive medicine, School of Public Health, Anhui Medical University, Hefei 230032, Anhui, China. ${ }^{5}$ School of Public Health, University of Adelaide, Adelaide, SA 5005, Australia.

Received: 3 June 2019 Accepted: 7 November 2019

Published online: 20 November 2019

\section{References}

1. World Health Organization. 2016. Fact Sheet on Mental Disorders. Available:http://www.who.int/mediacentre/factsheets/fs396/en/(accessed 1st June, 2016).
2. World Health Organization. 2015. Health in 2015: From MDGs to SDGs. Available: http://www.who.int/gho/publications/mdgs-sdgs/en/(accessed 1st June, 2016).

3. Huang $Y$, Wang $Y$, Wang H, Liu Z, Yu X, Yan J, Yu Y, Kou C, Xu X, Lu J, et al. Prevalence of mental disorders in China: a cross-sectional epidemiological study. Lancet Psychiat. 2019;6(3):211-24.

4. Xu J, Wang J, Wimo A, Qiu C. The economic burden of mental disorders in China, 2005-2013: implications for health policy. BMC Psychiatry. 2016;16:137.

5. Tong L, Li K, Zhou Q. Season, sex and age as modifiers in the association of psychosis morbidity with air pollutants: a rising problem in a Chinese metropolis. Sci Total Environ. 2016;541:928-33.

6. Song J, Zheng L, Lu M, Gui L, Xu D, Wu W, Liu Y. Acute effects of ambient particulate matter pollution on hospital admissions for mental and behavioral disorders: a time-series study in Shijiazhuang, China. Sci Total Environ. 2018:636:205-11.

7. Buoli M, Grassi S, Caldiroli A, Carnevali GS, Mucci F, lodice S, Cantone L, Pergoli $\mathrm{L}$, Bollati $\mathrm{V}$. Is there a link between air pollution and mental disorders? Environ Int. 2018;118:154-68.

8. Hansen A, Bi P, Nitschke M, Ryan P, Pisaniello D, Tucker G. The effect of heat waves on mental health in a temperate Australian city. Environ Health Perspect. 2008:116(10):1369-75.

9. Wang X, Lavigne E, Ouellette-kuntz H, Chen BE. Acute impacts of extreme temperature exposure on emergency room admissions related to mental and behavior disorders in Toronto, Canada. J Affect Disord. 2014;155:154-61.

10. Page LA, Hajat S, Kovats RS, Howard LM. Temperature-related deaths in people with psychosis, dementia and substance misuse. Br J Psychiatry. 2012;200(6):485-90.

11. Peng Z, Wang $Q$, Kan $H$, Chen $R$, Wang W. Effects of ambient temperature on daily hospital admissions for mental disorders in Shanghai, China: a time-series analysis. Sci Total Environ. 2017:590-591:281-6.

12. Kovats RS, Hajat S. Heat stress and public health: a critical review. Annu Rev Public Health. 2008:29:41-55.

13. Ho HC, Knudby A, Xu Y, Hodul M, Aminipouri M. A comparison of urban heat islands mapped using skin temperature, air temperature, and apparent temperature (Humidex), for the greater Vancouver area. Sci Total Environ. 2016:544:929-38.

14. Krstic G. Apparent temperature and air pollution vs. elderly population mortality in Metro Vancouver. PLOS ONE. 2011;6(9):e25101.

15. Gasparrini A, Armstrong B. Distributed lag non-linear models. Stat Med. 2010:29:2224-34.

16. Yi W, Zhang X, Gao J, Wei Q, Pan R, Duan J, Xu Z, Zhang Y, Bai L, Cheng Q, et al. Examining the association between apparent temperature and admissions for schizophrenia in Hefei, China, 2005-2014: A time-series analysis. Sci Total Environ. 2019(672):1-6.

17. Basu R, Gavin L, Pearson D, Ebisu K, Malig B. Examining the association between apparent temperature and mental health-related emergency room visits in California. Am J Epidemiol. 2018;187(4):726-35.

18. Carlsen HK, Oudin A, Steingrimsson S, Oudin AD. Ambient Temperature and Associations with Daily Visits to a Psychiatric Emergency Unit in Sweden. Int J Environ Res Public Health. 2019;16(2).

19. Shiloh R, Weizman A, Epstein $Y$, Rosenberg SL, Valevski A, Dorfman-Etrog P, Wiezer N, Katz N, Munitz H, Hermesh H. Abnormal thermoregulation in drug-free male schizophrenia patients. Eur Neuropsychopharmacol. 2001; 11(4):285-8

20. Kim Y, Kim H, Honda Y, Guo YL, Chen BY, Woo JM, Ebi KL. Suicide and ambient temperature in east Asian countries: a time-stratified case-crossover analysis. Environ Health Perspect. 2016;124(1):75-80.

21. Anderson CA. Temperature and aggression: ubiquitous effects of heat on occurrence of human violence. Psychol Bull. 1989;106(1):74-96.

22. Jimenez-Trevino L, Saiz PA, Garcia-Portilla MP, Blasco-Fontecilla H, Carli V, losue M, Jaussent I, Lopez-Castroman J, Vaquero-Lorenzo C, Sarchiapone M, et al. 5-HTTLPR-brain-derived neurotrophic factor (BDNF) gene interactions and early adverse life events effect on impulsivity in suicide attempters. World J Biol Psychiatry. 2019;20(2):137-49.

23. Brewerton TD, Putnam KT, Lewine R, Risch SC. Seasonality of cerebrospinal fluid monoamine metabolite concentrations and their associations with meteorological variables in humans. J Psychiatr Res. 2018;99:76-82.

24. Finsterer J, Reining-Festa A, Stollbergr C, Voigtlander T. Dopaminedeficiency-enhanced hyperthermia and rhabdomyolysis during a heat wave in a metachromatic leucodystrophy heterozygote with metabolic myopathy. Acta Neurol Belg. 2011;111(4):321-4. 
25. Calkins MM, Isaksen TB, Stubbs BA, Yost MG, Fenske RA. Impacts of extreme heat on emergency medical service calls in King County, Washington, 20072012: relative risk and time series analyses of basic and advanced life support. Environ Health. 2016;15:13.

26. Stöllberger C. LWFJ: heat-related side-effects of neurological and nonneurological medication may increase heatwave fatalities. Eur I Neurol. 2009;7(16):879-82.

27. Hodgins S, Piatosa MJ, Schiffer B. Violence among people with schizophrenia: phenotypes and neurobiology. Curr Top Behav Neurosci. 2014;17:329-68.

28. Martin-Latry K, Goumy MP, Latry P, Gabinski C, Begaud B, Faure I, Verdoux H. Psychotropic drugs use and risk of heat-related hospitalisation. Eur Psychiatry. 2007;22(6):335-8.

\section{Publisher's Note}

Springer Nature remains neutral with regard to jurisdictional claims in published maps and institutional affiliations.

Ready to submit your research? Choose BMC and benefit from:

- fast, convenient online submission

- thorough peer review by experienced researchers in your field

- rapid publication on acceptance

- support for research data, including large and complex data types

- gold Open Access which fosters wider collaboration and increased citations

- maximum visibility for your research: over $100 \mathrm{M}$ website views per year

At $\mathrm{BMC}$, research is always in progress.

Learn more biomedcentral.com/submissions 